\title{
Comparative Study of Streptococcus mutans Extracellular Glycosyltransferases by Isoelectric Focusing
}

\author{
By HIDEAKI TSUMORI, ATSUNARI SHIMAMURA AND \\ HIDEHIKO MUKASA* \\ Department of Chemistry, National Defense Medical College, 2, Namiki 3-chome, Tokorozawa, \\ Saitama 359, Japan
}

(Received 21 April 1983; revised 9 June 1983)

\begin{abstract}
Extracellular glycosyltransferases from 17 strains of Streptococcus mutans were examined by analytical isoelectric focusing. Three kinds of glucosyltransferase: highly-branched-1,6- $\alpha$-Dglucan synthetase, 1,3- $\alpha$-D-glucan synthetase and 1,6- $\alpha$-D-glucan synthetase, were excreted from serotype $a, d$ and $g$ strains. The enzymes of serotype $a$ strains were distinguishable from those of serotypes $d$ and $g$ by differences in their $\mathrm{pI}$ values. Serotype $c, e$ and $f$ strains excreted basic glucosyltransferase and acidic fructosyltransferase. Serotype $b$ strains also excreted the glucosyland fructosyltransferases, but the pI values were different from those of the enzymes from the other serotypes. Thus, $S$. mutans strains could be divided into four groups by analytical isoelectric focusing of glycosyltransferases which corresponded well to the four genetic groups.
\end{abstract}

\section{INTRODUCTION}

Streptococcus mutans is a cariogenic micro-organism which secretes glucosyltransferases and, in some serotypes, fructosyltransferase (Carlsson, 1970; Schachtele et al., 1975; Ciardi et al., 1976). Highly-branched-1,6- $\alpha$-D-glucan synthetases have been purified from $S$. mutans 6715 (serotype $g$; pI 4.1) (Shimamura et al., 1982) and HS6 (serotype $a ; \mathrm{pI} 4 \cdot 2$ and 4.5) (Tsumori et al., 1983). A basic glucosyltransferase (pI 8.5) (Mukasa et al., 1982b) and an acidic fructosyltransferase (pI 4.6) (Carlsson, 1970) have been purified from $S$. mutans serotype $c$ strains. 1,3- $\alpha-$ D-glucan synthetases have also been purified from $S$. mutans B13 (serotype $d$ ) (Fukushima et al., 1981) and strain 6715 (Fukui et al., 1982). By the cooperative action of these enzymes, a sticky, water-insoluble polysaccharide is synthesized from sucrose which is considered to be a major factor in the accumulation of $S$. mutans on smooth tooth surfaces (Gibbons \& Nygaard, 1968; Mukasa \& Slade, 1973c).

Strains of $S$. mutans have been classified into seven serotypes on the basis of cell wall polysaccharide antigens (Bratthall, 1972; Perch et al., 1974). Certain similarities among these serotypes have been reported based on DNA-DNA hybridization (Coykendall, 1974), SDS-PAGE of whole cell proteins (Russell, 1976) and biochemical traits (Shklair \& Keene, 1974).

In this paper, we have analysed the distribution of extracellular glycosyltransferases among the seven $S$. mutans serotypes by analytical isoelectric focusing over a wide $\mathrm{pH}$ range. Four patterns were obtained that support the four groups of serotypes. (A preliminary report of this work was given at the 54th Annual Meeting of the Japanese Biochemical Society, Sendai, Japan, October, 1981).

\section{METHODS}

Strains and culture conditions. The strains of $S$. mutans used in this study were: HS6, E49, OMZ61 (serotype a); FA1, BHT (b); Ingbritt, C67-1, MT6R (c); B13 (d); LM7, MT703 (e); SE11, OMZ175 ( $f$; 6715, K1R, OMZ65, AHT $(g)$. Strains HS6, OMZ61, FA1, BHT, B13, 6715 and K1R were kindly provided by Dr H. D. Slade (Department of Oral Biology, School of Dentistry, University of Colorado Health Science Center, Denver, Colo.). 
Strain C67-1 was a gift from Dr T. Ogawa (Department of Microbiology, Josai Dental University, Saitama, Japan). The other strains were kindly provided by Dr S. Hamada (Department of Dental Research, National Institute of Health, Shinagawa-ku, Tokyo, Japan).

With the exception of strains FA1, BHT, SE11 and OMZ175, bacteria were grown for 10 to $15 \mathrm{~h}$ at $37^{\circ} \mathrm{C}$ in a chemically defined medium ( $10 \mathrm{ml}$ ) (Terleckyj et al., 1975) supplemented with $0 \cdot 1 \%(\mathrm{w} / \mathrm{v})$ Tween 80 for the strains of serotypes $a, d$ and $g$ and with $1 \%(\mathrm{w} / \mathrm{v})$ Tween 80 for the strains of serotypes $c$ and $e$. Streptococcus mutans FA1, BHT, SE11 and OMZ175 were grown for $16 \mathrm{~h}$ at $37^{\circ} \mathrm{C}$ in Todd-Hewitt broth (1 litre) treated with invertase and fortified with fructose and salts (Mukasa et al., 1979). The cultures were all harvested at late-exponential phase when the $\mathrm{pH}$ reached $5 \cdot 0$. The turbidity of the cultures at $550 \mathrm{~nm}$ was between $4 \cdot 0$ and $5 \cdot 0$. The cell-free culture supernatants obtained by centrifugation for $15 \mathrm{~min}$ at $1200 \mathrm{~g}$ were used directly as glycosyltransferase sources for the strains of serotypes $a, d$ and $g$. For serotypes $c$ and $e$, the cell-free culture supernatants were concentrated to $1 \mathrm{ml}$ with a mini-module equipped with a holotube $(1.2 \mathrm{~m} \times 0.8 \mathrm{~mm}$, molecular weight limit: 13000 , Asahi Chemical Industry, Tokyo, Japan) under reduced pressure (Mukasa et al., 1982b). For strains FA1, BHT, SE11 and $\mathrm{OMZ175}, 40 \%(\mathrm{v} / \mathrm{v})$ ethanol precipitates obtained from the cell-free culture supernatants were suspended in $20 \mathrm{ml}$ distilled water, and the insoluble materials were removed by centrifugation for $15 \mathrm{~min}$ at $38000 \mathrm{~g}$.

Analytical isoelectric focusing. A horizontal, polyacrylamide slab gel containing $1 \%(\mathrm{w} / \mathrm{v})$ Triton X-100 was used for analytical isoelectric focusing (Mukasa et al., 1982a,b). Enzyme solution (1 to $10 \mu 1$ ) was applied with a piece of glass fibre filter paper. After the focusing, the gel was incubated in $0.1 \mathrm{M}$-sodium phosphate buffer, $\mathrm{pH} 6.5$, containing sucrose $(43.9 \mathrm{mM})$, dextran T10 $\left(0.34 \mathrm{mg} \mathrm{ml}^{-1}\right)$ and merthiolate $(0.01 \%, \mathrm{w} / \mathrm{v})$ for $15 \mathrm{~h}$ at $37^{\circ} \mathrm{C}$. Raffinose (43.9 mM), recrystallized twice from $60 \%(\mathrm{v} / \mathrm{v})$ ethanol, was used to indicate fructosyltransferase activity (Carlsson, 1970). Polysaccharides, which accumulated in the gel during incubation, were stained by the periodic acid-Schiff base method (Kapitany \& Zebrowski, 1973) omitting the first fixing step which uses $12 \cdot 5 \%$ (w/v) TCA.

Materials. Yeast invertase (390 i.u. $\mathrm{ml}^{-1}$ at $20^{\circ} \mathrm{C}$ ) was obtained from Wako Pure Chemical Industry, Osaka, Japan. Ampholines and Dextran T10 were purchased from LKB and Pharmacia, respectively. All other chemicals were of analytical or reagent grade.

\section{RESULTS}

Extracellular glycosyltransferases from $S$. mutans were isoelectrofocused on a horizontal slab gel. After incubating the focused gel for $15 \mathrm{~h}$ at $37^{\circ} \mathrm{C}$ in a sucrose solution, highly-branched-1,6$\alpha$-D-glucan synthetase activities were detected as transparent, bulgy bands and 1,3- $\alpha$-D-glucan synthetase activities as white opaque bands on the gel.

Figure 1 shows focused patterns of our collection of purified glucosyltransferases from $S$. mutans strain 6715 (pI 4.1, Shimamura et al., 1982; pI 3.9, unpublished), Ingbritt (pI 8.5, Mukasa et al., 1982b) and HS6 (pI 4.2 and 4.5, Tsumori et al., 1983) and a fructosyltransferase (pI 4.6, Mukasa et al., 1982b). These enzymes were clearly distinguishable from each other in the gel according to their $\mathrm{pI}$ values. The focused pattern of glycosyltransferases from HS6 (a) grown in Todd-Hewitt broth was almost identical with the pattern from the same strain grown in a chemically defined medium (Fig. 2, lanes 1 and 2). The pattern of enzymes from Ingbritt (c) was also unaffected by growth conditions (lanes 5 and 6). However, as previously reported (Shimamura et al., 1983), the excretion of 1,6- $\alpha$-D-glucan synthetase from HS6 (a) was remarkably enhanced with increasing concentrations of Tween 80 (lanes 3 and 4). Since excessive excretion of this enzyme complicates a comparative study of glycosyltransferases, the lower concentration $(0 \cdot 1 \%, \mathrm{w} / \mathrm{v})$ of Tween 80 was added to the growth medium for serotypes $a, d$ and $g$ in this study. For serotypes $c$, and $e$, the higher concentration $(1 \%, \mathrm{w} / \mathrm{v})$ of Tween 80 was added to the medium, since enhancement of the excretion of glycosyltransferase was not so marked (Fig. 2, lane 7).

\section{Glycosyltransferases from serotype $a, d$ and $g$ strains}

The focused patterns of glycosyltransferases from eight strains of the serotypes $a, d$ and $g$ are shown in Fig. 3. Highly-branched-1,6- $\alpha$-D-glucan synthetases were detected at $\mathrm{pH} 4 \cdot 2$ and $4 \cdot 5$ (serotype $a$ strains), at $\mathrm{pH} 4.0$ and $4.2(d)$ and at $\mathrm{pH} 3.9$ and $4 \cdot 1(g)$ (Fig. $3 a$ ). 1,3- $\alpha$-D-glucan synthetases were also detected at pH 5.2, 4.8 and 4.9 for serotypes $a, d$ and $g$, respectively (Fig. $3 b$ ). After incubation in a sucrose solution and staining with the periodic acid-Schiff base method, another kind of glycosyltransferase from $6715(\mathrm{~g})$ was detected on the gel at $\mathrm{pH} 5 \cdot 5$ and 


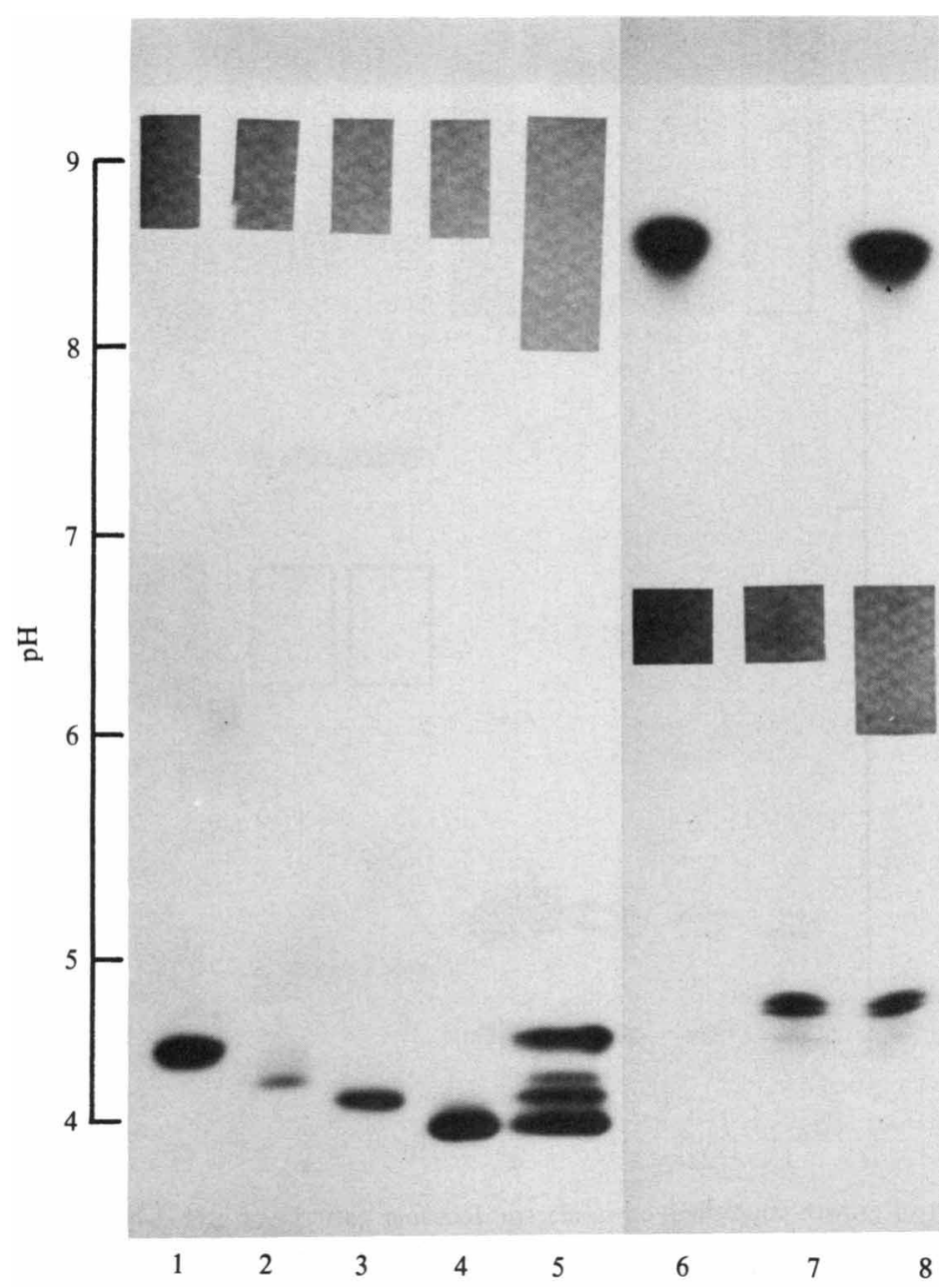

Fig. 1. Isoelectric focusing patterns of $S$. mutans purified glycosyltransferase activities stained using the periodic acid-Schiff base method. Lanes 1 to $8: S$. mutans HS6 (serotype $a$ ) glucosyltransferase, pI 4.5; HS6 glucosyltransferase, pI 4.2; $6715(\mathrm{~g})$ glucosyltransferase, pI 4.1; 6715 glucosyltransferase, pI 3.9; mixture of the purified glucosyltransferases from $S$. mutans HS6 and 6715; Ingbritt (c) basic glucosyltransferase, pI 8.5; Ingbritt fructosyltransferase, pI 4.6 ; mixture of the basic glucosyltransferase and fructosyltransferase.

5.8. The enzyme was not activated by exogenous dextran and excretion into the culture medium was greatly enhanced by Tween 80 . From analysis of its product, the enzyme was identified as a 1,6- $\alpha$-D-glucan synthetase (Shimamura et al., 1983). 1,6- $\alpha$-D-glucan synthetases were also detected at $\mathrm{pH} 4 \cdot 8,4.9$ and 5.6 from serotype $a$, and at pH 5.4, 5.6 and 5.8 from serotype $d$ (Fig. $3 a$ ). Thus, the focused pattern of the enzymes from the serotype $d$ strain was very close to those of serotype $g$ strains (Fig. $3 a$ ), and the patterns of serotype $a$ strains were clearly distinguishable from those of serotypes $d$ and $g$ (Fig. $3 a$ ). The focused pattern of AHT $(g)$ was intermediate between the pattern of serotype $d$ and that of serotype $g$. The highly-branched-1,6- $\alpha$-D-glucan synthetase was focused in the same position as that of serotype $d$ (Fig. $3 a$ ), the 1,3- $\alpha$-D-glucan synthetase band coincided with those of the other strains of serotype $g$ (Fig. $3 b$ ), and the focused bands of 1,6- $\alpha$-D-glucan synthetase coincided in position with those of both serotypes $d$ and $g$. No fructosyltransferase activity was detected under the assay conditions employed. 


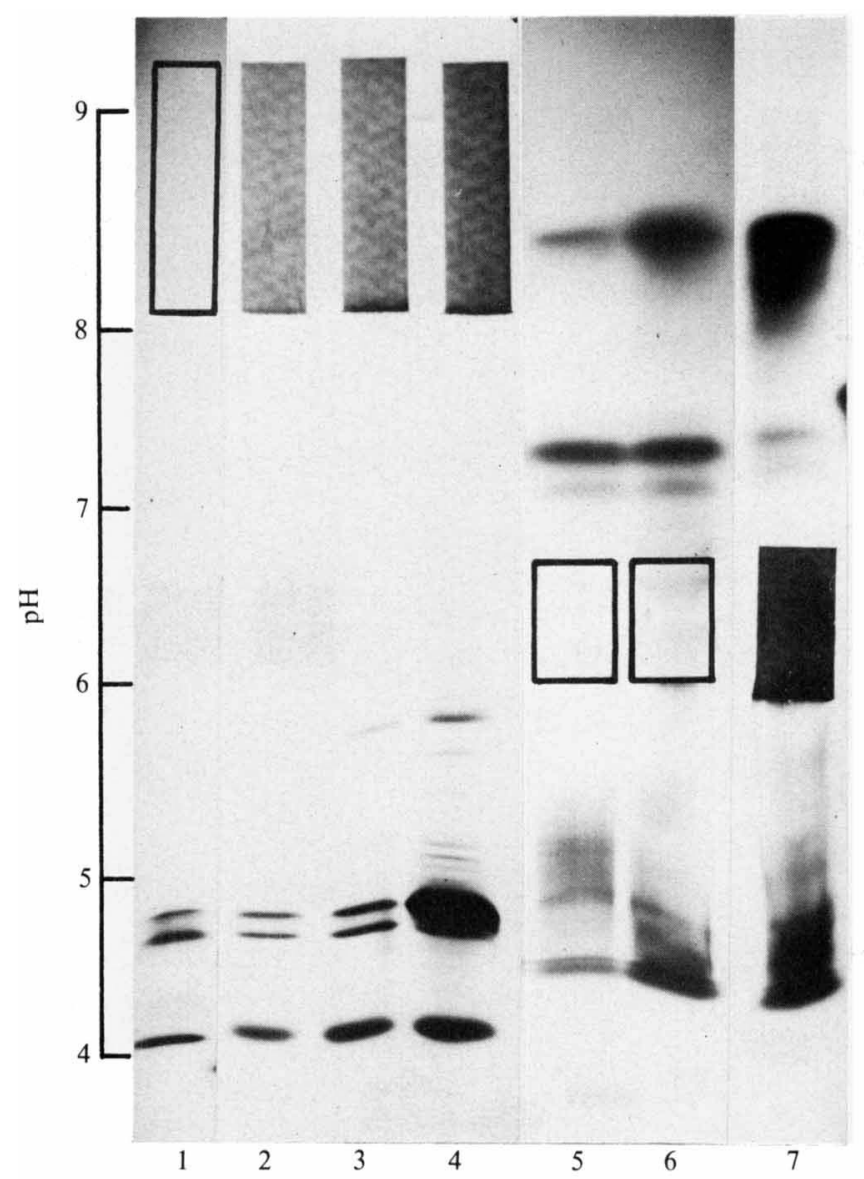

Fig. 2. Effect of growth conditions on isoelectric focusing patterns of glycosyltransferases from $S$. mutans serotypes $a$ and $c$. Crude enzyme preparations were used from HS6 (lanes 1 to 4) and Ingbritt (lanes 5 to 7) grown in modified Todd-Hewitt broth (lanes 1 and 5) and grown in chemically defined medium containing $0 \%$ (lanes 2 and 6$), 0 \cdot 1 \%(w / v)$ (lane 3$)$ and $1 \%(w / v)$ (lanes 4 and 7 ) Tween 80. Pieces of glass fibre filter paper were put on the gel surface and the enzyme solutions were applied to them $(\square)$.

\section{Glycosyltransferases from serotype $b$ strains}

The focused patterns of glycosyltransferases from serotype $b$ strains are shown in Fig. 4 . The staining of the focused gel revealed two or three active bands (pI 4.0, 4.6 and 4.8) using sucrose as substrate (Fig. $4 a$ ). Fructosyltransferase activity was identified using raffinose as substrate. The position of the fructosyltransferase band corresponded to that of the sucrose-active band at $\mathrm{pH} 4 \cdot 0$. These active bands did not coincide in position with the purified enzymes from serotypes $a, c$ and $g$ (Fig. 4).

\section{Glycosyltransferases from serotype $c, e$ and $f$ strains}

Figure 5 shows the focused patterns of glycosyltransferases from the seven strains of serotypes $c, e$ and $f$. All strains produced basic glucosyltransferase (pI 8.5-8.6) and acidic fructosyltransferase (pI 4.5-4.6), as reported previously from Ingbritt (c) (Mukasa et al., 1982b). The pronounced tailing of fructosyltransferase bands on gels could be due to insufficient dissociation of aggregated forms by Triton X-100 (Fig. 5, lanes 2, 3 and 5 to 7). The other glycosyltransferase activity bands were detected in multiple forms at $\mathrm{pH} 7$ to 8 (Fig. 5) and most of these components disappeared during prolonged storage at $4{ }^{\circ} \mathrm{C}$. 


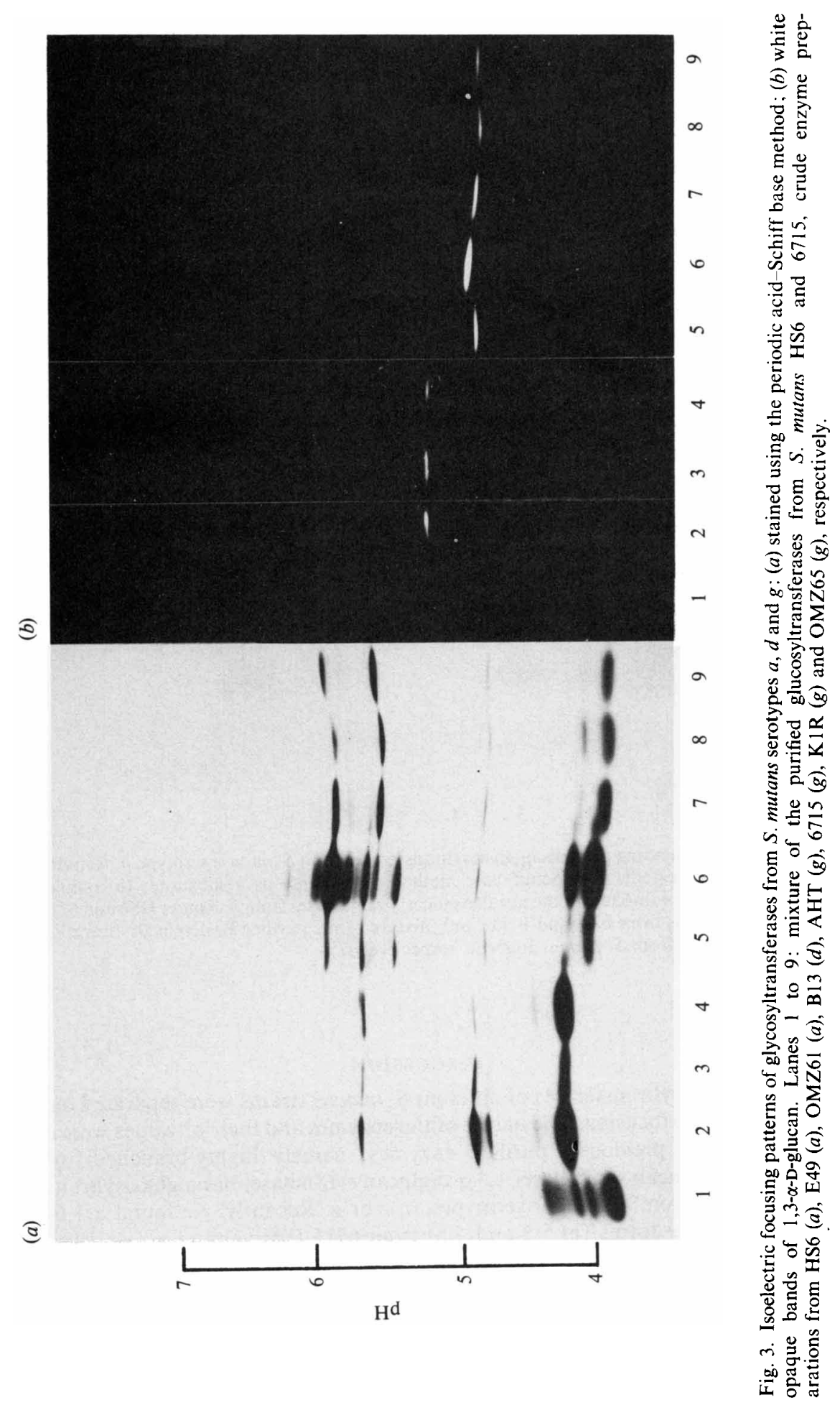


(a)

(b)

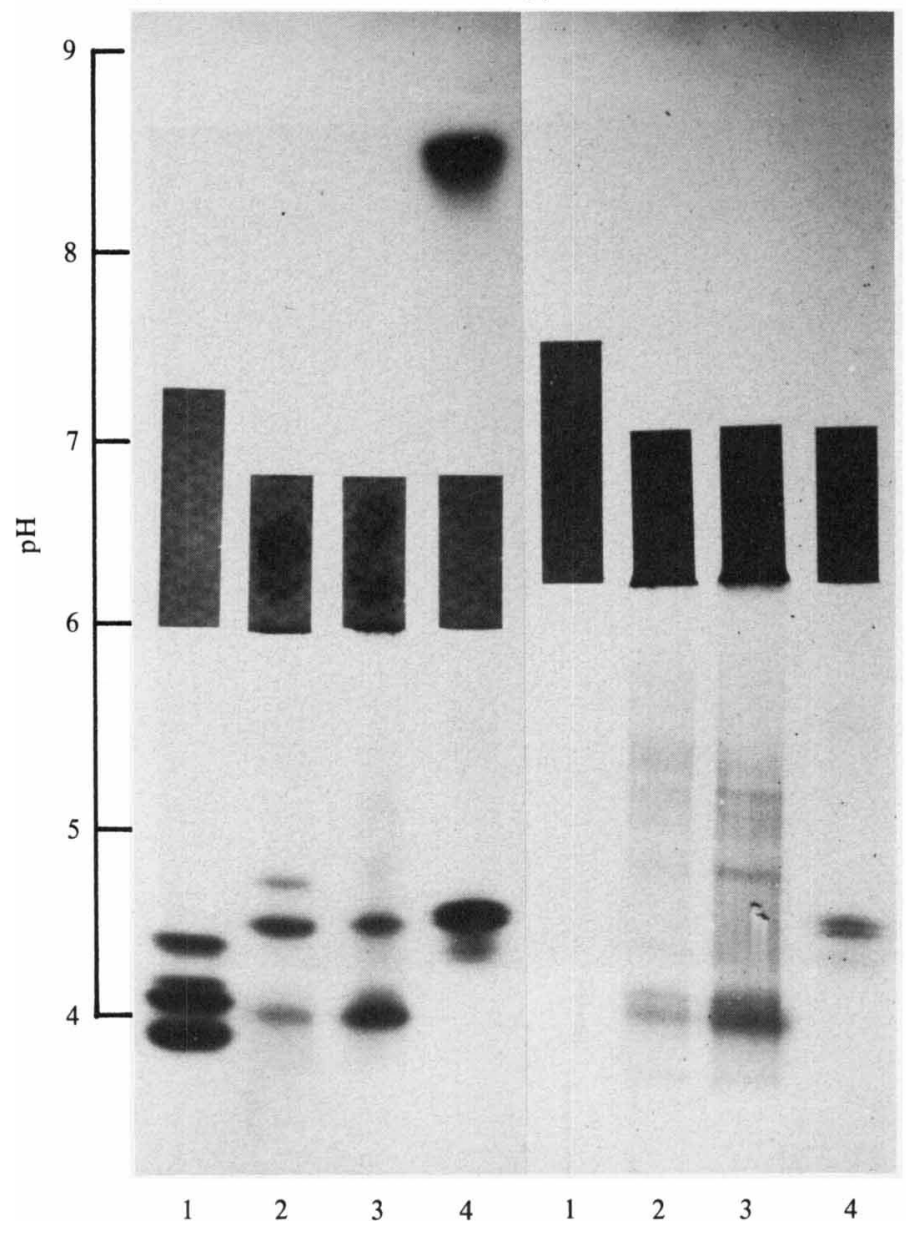

Fig. 4. Isoelectric focusing patterns of glycosyltransferases from $S$. mutans serotype $b$. Activities were stained using the periodic acid-Schiff base method: $(a)$ sucrose as a substrate; $(b)$ raffinose as a substrate. Lanes 1 to 4 : mixture of the purified glucosyltransferases from $S$. mutans HS6 and 6715 , crude enzyme preparations from FA1 and BHT, and mixture of the purified basic glucosyltransferase and fructosyltransferase from $S$. mutans Ingbritt, respectively.

\section{DISCUSSION}

Extracellular glycosyltransferases of different $S$. mutans strains were separated on horizontal slab gels by isoelectric focusing. The nature of the enzymes and their $\mathrm{pI}$ values were determined by comparison with previously purified enzymes; namely highly-branched-1,6- $\alpha$-D-glucan synthetase, 1,6- $\alpha$-D-glucan synthetase, 1,3- $\alpha$-D-glucan synthetase, basic glucosyltransferase and fructosyltransferase from $S$. mutans serotypes, $a, c$ or $g$. Recently, we found a 1,6- $\alpha$-D-glucan synthetase in multiple forms (pI 5.5 and 5.8) from 6715 (Shimamura et al., 1983), and this enzyme was also used as one of the glycosyltransferase markers. Highly-branched-1,6- $\alpha$-Dglucan synthetase, 1,6- $\alpha$-D-glucan synthetase and 1,3- $\alpha$-D-glucan synthetase were immunologically distinct from each other (Shimamura et al., 1983). All of the serotype $d$ and $g$ strains excreted highly-branched-1,6- $\alpha$-D-glucan synthetase, 1,6- $\alpha$-D-glucan synthetase and 1,3- $\alpha$-Dglucan synthetase with slight differences of pI values among $d$ and $g$ strains. Guggenheim \& Newbrun (1969) obtained by preparative isoelectric focusing, pI 4.24, 5.00 and 5.65 components 


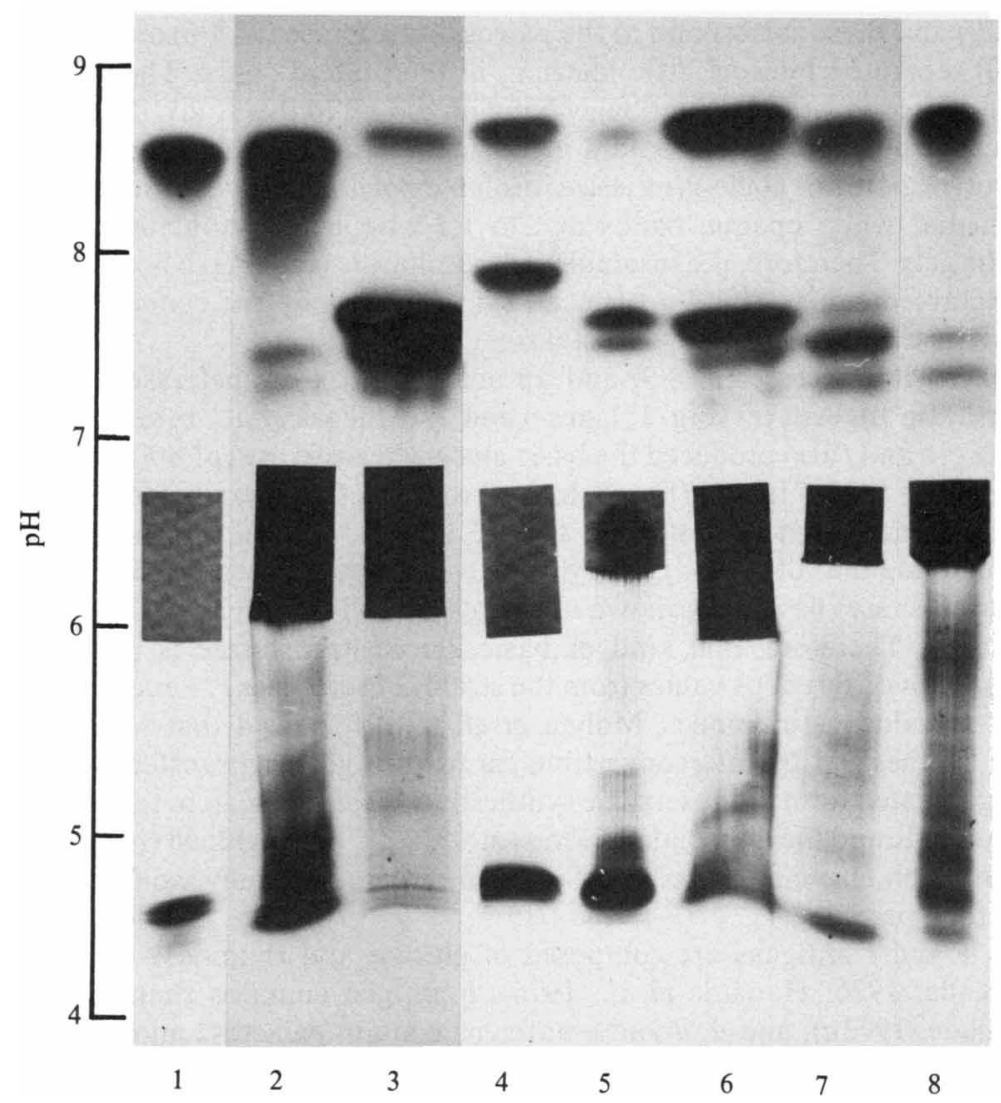

Fig. 5. Isoelectric focusing patterns of glycosyltransferases from $S$. mutans serotypes $c, e$ and $f$ stained using the periodic acid-Schiff base method. Lanes 1 to 8 : mixture of the purified basic glucosyltransferase and fructosyltransferase from $S$. mutans Ingbritt, crude enzyme preparations from Ingbritt $(c)$, C67-1 $(c), \operatorname{MT6R}(c), \operatorname{LM} 7(e), \operatorname{MT703}(e), \operatorname{SE} 11(f)$ and OMZ175 $(f)$, respectively.

of 1,3- $\alpha$-D-glucan synthetase from OMZ176 $(d)$, of which the pI 5.00 component is compatible with the pI 4.8 1,3- $\alpha$-D-glucan synthetase in this study. Bulkacz \& Hill (1977) also detected pI $4 \cdot 6,5 \cdot 0$ to $5 \cdot 2$ and $5 \cdot 6$ components of glucosyltransferases from strain 6715 . It is impossible to correlate these with the three kinds of glucosyltransferases in this study, since their enzymological properties have not been described. Recently, $S$. mutans serotype $h$ was isolated from the dental plaque of monkeys (Beighton et al., 1981). Since immunological properties and SDS-PAGE patterns have shown that serotype $h$ strains were closely related to strains of genetic group III (i.e. serotypes $d$ and $g$ ), it is possible that the glucosyltransferases from serotype $h$ strains might exhibit a focused pattern similar to those of serotypes $d$ and $g$.

Serotype $a$ strains also excreted highly-branched-1,6- $\alpha$-D-glucan synthetase (pI $4 \cdot 2$ and $4 \cdot 5$ ), 1,3- $\alpha$-D-glucan synthetase (pI 5.2) and 1,6- $\alpha$-D-glucan synthetase which focused at $\mathrm{pH} 4 \cdot 8,4.9$ and 5.6 (Fig. $3 a$ ). There are certain differences between serotype $a$ and serotype $d$ and $g$ glucosyltransferases: the 1,3- $\alpha$-D-glucan synthetase from serotype $a$ had a higher $\mathrm{pI}$ value $(5 \cdot 2)$ than those of serotypes $d$ and $g(4 \cdot 8$ and $4 \cdot 9$, respectively), while 1,6- $\alpha$-D-glucan synthetase from serotype $a$ had lower pI values (4.8 and 4.9) than those of serotypes $d$ and $g(5.4$ to 5.8$)$.

Streptococcus mutans serotype $b$ showed a unique focused pattern of a glucosyltransferase (pI 4.6 and 4.8) and a fructosyltransferase (pI 4.0) (Fig. 4). A high molecular weight ( $>800000)$ enzyme aggregate with glucosyl- and fructosyltransferase activities was isolated by Scales et al. (1975). The two activities were resolved during PAGE in the presence of Tween 80 (Figures \& 
Edwards, 1979) and these correspond to the glucosyltransferase (pI 4.6) and the fructosyltransferase (pI 4.0) separated by isoelectric focusing in the present study. The glucosyltransferase activity was detected as a transparent bulgy band on the gel in this study. Therefore, the glucan synthesized could be expected to contain a considerable amount of $1,6-\alpha$-D-glucose residues. Although serotype $b$ strains could synthesize insoluble polysaccharide during growth in sucrosecontaining media, white opaque bands due to 1,3- $\alpha$-D-glucan synthetase activity were not detected on the gels. Therefore, the insoluble polysaccharide could have been synthesized either by an undetectable amount of 1,3- $\alpha$-D-glucan synthetase or by the cooperative action of the glucosyltransferase and the fructosyltransferase.

A basic glucosyltransferase (pI 8.5) and an acidic fructosyltransferase (pI 4.5) have been purified from strain Ingbritt (c) (Fig. 1, lanes 6 and 7) (Mukasa et al., 1982b). The other strains from serotypes $c, e$ and $f$ also produced the basic glucosyltransferase (pI 8.5 to 8.6) and the acidic fructosyltransferase (pI 4.5 to 4.6 ) (Fig. 5, lanes 2 to 7 ). Activity bands focused in the range of $\mathrm{pH} 7$ to 8 disappeared during prolonged storage at $4{ }^{\circ} \mathrm{C}$ and during the purification steps, possibly by changing into the basic glucosyltransferase, as suggested by Mukasa et al. $(1982 b)$. The glucosyltransferases have been shown to be antigenically identical within serotypes $c, e$ and $f$ (Russell, 1979). Therefore, one kind of basic glucosyltransferase is probably excreted in multiple forms with different pl values from the strains of serotypes $c, e$ and $f$, but the reason for the different pI values is unknown. Mohan et al. (1979) showed that soluble and insoluble glucans were synthesized by interconvertible forms of a glucosyltransferase from serotype $c$ strains; the aggregated form of the enzyme synthesized 1,3- $\alpha$-D-glucan in the presence of $1.55 \mathrm{M}$ ammonium sulphate and the dissociated form synthesized 1,6- $\alpha$-D-glucan (Newman et al., 1980). It is not clear which enzyme focused on the gel in the present study would correspond to the enzyme that they prepared.

Serotype $c, e$ and $f$ antigens are composed of glucose and rhamnose (Linzer et al., 1976; Hamada \& Slade, 1976; Hamada et al., 1976), $b$ antigen contains rhamnose and galactose (Mukasa \& Slade, 1973 $a$ ), and $a, d$ and $g$ antigens contain galactose and glucose (Mukasa \& Slade, 1973b; Linzer \& Slade, 1974; Iacono et al., 1975). The $a$ antigen is immunologically partially identical with $d$ and $g$ antigens. Coykendall (1974) has divided $S$. mutans into four genetic groups and also reported that $S$. mutans $a$ and $d(g)$ strains were genetically partially identical. Relationships between $S$. mutans serotypes have been reported as $d>a \gg b>c$ based on the electrophoretic mobility of mannitol-1-phosphate dehydrogenase (Brown \& Patterson, 1972), $a=d=g \gg b>c=e=f$ based on antigenic similarity of glucosyltransferases (Smith \& Taubman, 1977), and $a, b, d \gg c, e, f, g$ according to a comparative study of intracellular invertases (Tanzer et al., 1977). The data presented here show that the four groups are also apparent from isoelectric focusing patterns of extracellular glycosyltransferase activity.

\section{REFERENCES}

Beighton, D., Russell, R. R. B. \& HAYday, H. (1981). The isolation and characterization of Streptococcus mutans serotype $h$ from dental plaque of monkeys (Macaca fascicularis). Journal of General Microbiology 124, 271-279.

BRATTHALL, D. (1972). Immunofluorescent identification of Streptococcus mutans. Odontologisk Revy 23, 181-196.

Brown, A. T. \& Patterson, C. E. (1972). Heterogeneity of Streptococcus mutans strains based on their mannitol-1-phosphate dehydrogenase: criterion for rapid classification. Infection and Immunity 6, 422424.

BulKaCZ, J. \& HiLl, J. H. (1977). Glucosyltransferases from Streptococcus mutans and a non-plaque forming mutant. Archives of Oral Biology 22, 119-123.

CARLSSON, J. (1970). A levansucrase from Streptococcus mutans. Caries Research 4, 97-113.
Ciardi, J. E., Hageage, Jr, G. J. \& Wittenberger, C. L. (1976). Multicomponent nature of the glucosyltransferase system of Streptococcus mutans. Journal of Dental Research 55 (Special Issue C), C87-C96.

CoYkendall, A. L. (1974). Four types of Streptococcus mutans based on their genetic, antigenic and biochemical characteristics. Journal of General Microbiology 83, 327-338.

FIgURES, W. R. \& EDWARds, J. R. (1979). Resolution of the glucosyltransferase activities from two strains of Streptococcus mutans by polyacrylamide gel electrophoresis in the presence of Tween 80. Biochimica et biophysica acta 577, 142-146.

Fukui, K., Moriyama, T., Miyake, Y., Mizutani, K. \& TANAKA, O. (1982). Purification and properties of glucosyltransferase responsible for water-insoluble glucan synthesis from Streptococcus mutans. Infection and Immunity 37, 1-9. 
Fukushima, K., Motoda, R., Takada, K. \& Ikeda, T (1981). Resolution of Streptococcus mutans glucosyltransferases into two components essential to waterinsoluble glucan synthesis. FEBS Letters 128, 213 216.

Gibbons, R. J. \& NyGaARd, M. (1968). Synthesis of insoluble dextran and its significance in the formation of gelatinous deposits by plaque-forming streptococci. Archives of Oral Biology 13, 1249-1262.

GuggenHeIM, B. \& NewbRun, E. (1969). Extracellular glucosyltransferase activity of an HS strain of Streptococcus mutans. Helvetica odontologica acta 13, 84-97.

Hamada, S. \& Slade, H. D. (1976). Purification and immunochemical characterization of type $e$ polysaccharide antigen of Streptococcus mutans. Infection and Immunity 14, 68-76.

Hamada, S., Gill, K. \& Slade, H. D. (1976). Chemical and immunological properties of type $f$ polysaccharide antigen of Streptococcus mutans. Infection and Immunity 14, 203-211.

Iacono, V. J., Taubman, M. A., Smith, D. J. \& Levine, M. J. (1975). Isolation and immunochemical characterization of the group-specific antigen of Streptococcus mutans 6715. Infection and Immunity 11, 117-128.

KaPITANY, R. A. \& Zebrowski, E. J. (1973). A high resolution PAS stain for polyacrylamide gel electrophoresis. Analytical Biochemistry 56, 361-369.

Linzer, R. \& Slade, H. D. (1974). Purification and characterization of Streptococcus mutans group $d$ cell wall polysaccharide antigen. Infection and Immunity 10, 361-368.

Linzer, R., Gill, K. \& Slade, H. D. (1976). Chemical composition of Streptococcus mutans type $c$ antigen: comparison to type $a, b$ and $d$ antigens. Journal of Dental Research 55 (Special Issue A), A109-A115.

Mohan, S. B., Newman, B. M. \& Cole, J. A. (1979). The interconversion of dextransucrase and mutansucrase activities from cariogenic strains of Streptococcus mutans. FEMS Microbiology Letters 5, 69-72.

Mukasa, H. \& Slade, H. D. (1973a). Structure and immunological specificity of the Streptococcus mutans group $b$ cell wall antigen. Infection and Immunity 7, 578-585.

Mukasa, H. \& Slade, H. D. (1973b). Extraction, purification, and chemical and immunological properties of the Streptococcus mutans group " $a$ " polysaccharide cell wall antigen. Infection and Immunity 8, 190-198.

Mukasa, H. \& Slade, H. D. (1973c). Mechanism of adherence of Streptococcus mutans to smooth surfaces. I. Role of insoluble dextran-levan synthetase enzymes and cell wall polysaccharide antigen in plaque formation. Infection and Immunity 8, 555-562.

Mukasa, H., Shimamura, A. \& Tsumori, H. (1979). Effect of salts on water-insoluble glucan formation by glucosyltransferase of Streptococcus mutans. Infection and Immunity 23, 564-570.

Mukasa, H., Shimamura, A. \& Tsumori, H. (1982a). Direct activity stains for glycosidase and glucosyl- transferase after isoelectric focusing in horizontal polyacrylamide gel layers. Analytical Biochemistry 123, 276-284.

Mukasa, H., Shimamura, A. \& Tsumori, H. (1982b). Purification and characterization of basic glucosyltransferase from Streptococcus mutans serotype $c$. Biochimica et biophysica acta 719, 81-89.

Newman, B. M., White, P., Mohan, S. B. \& Cole, J. A. (1980). Effect of dextran and ammonium sulphate on the reaction catalysed by a glucosyltransferase complex from Streptococcus mutans. Journal of General Microbiology 118, 353-366.

Perch, B., KJEMS, E. \& RaVN, T. (1974). Biochemical and serological properties of Streptococcus mutans from various human and animal sources. Acta pathologica et microbiologica scandinavica Section B 82, 357-370.

Russell, R. R. B. (1976). Classification of Streptococcus mutans strains by SDS gel electrophoresis. Microbios Letters 2, 55-59.

Russell, R. R. B. (1979). Glycosyltransferases of Streptococcus mutans strain Ingbritt. Microbios 23, 135-146.

Scales, W. R., Long, L. W. \& Edwards, J. R. (1975). Purification and characterization of a glycosyltransferase complex from the culture broth of Streptococcus mutans FA1. Carbohydrate Research 42, 325338.

Schachtele, C. F., StaAt, R. H. \& HaRlander, S. K. (1975). Dextranases from oral bacteria: inhibition of water-insoluble glucan production and adherence to smooth surfaces by Streptococcus mutans. Infection and Immunity 12, 309-317.

Shimamura, A., Tsumori, H. \& Mukasa, H. (1982). Purification and properties of Streptococcus mutans extracellular glucosyltransferase. Biochimica et biophysica acta 702, 72-80.

Shimamura, A., Tsumori, H. \& Mukasa, H. (1983). Three kinds of extracellular glucosyltransferases from Streptococcus mutans 6715 (serotype g). FEBS Letters 157, 79-84.

ShKLAIR, I. L. \& KEENE, M. J. (1974). A biochemical scheme for the separation of the five varieties of Streptococcus mutans. Archives of Oral Biology 19, 1079-1081.

Smith, D. J. \& Taubman, M. A. (1977). Antigenic relatedness of glucosyltransferase enzymes from Streptococcus mutans. Infection and Immunity 15, 91103.

TANZer, J. M., Brown, A. T., Mcinerney, M. F. \& WoOdIEL, F. N. (1977). Comparative study of invertases of Streptococcus mutans. Infection and Immunity 16, 318-327.

Terleckyj, B., Willett, N. P. \& Shockman, G. D. (1975). Growth of several cariogenic strains of oral streptococci in a chemically defined medium. Infection and Immunity 11, 649-655.

Tsumori, H., Shimamura, A. \& Mukasa, H. (1983). Purification and properties of extracellular glucosyltransferases from Streptococcus mutans serotype $a$. Journal of General Microbiology 129, 3251-3259. 